\title{
Blood ozonization in patients with mild to moderate COVID-19 pneumonia: a single centre experience: reply
}

\author{
Amato De Monte ${ }^{1} \cdot$ Giovanni Sermann $^{1} \cdot$ Emanuela Sozio $^{2} \cdot$ Francesco Sbrana $^{3}$ (1) $\cdot$ Carlo Tascini $^{2}$
}

Received: 30 December 2020 / Accepted: 4 January 2021 / Published online: 3 February 2021

c) Società Italiana di Medicina Interna (SIMI) 2021

\section{Dear Editor,}

Chirumbolo et al. in their letter [1] stigmatize that in our patients, we performed a pre-test for assessing ozone effectiveness instead of a 3 weeks treatment as they propose, extending ozone administration even in SIMEU phenotype 4 or worst. On the contrary, we confirm that our full programmed treatment was exactly that described in our paper [2]. The pathophysiological reasoning for our therapeutic approach has been based on the described effects of systemic ozonation to improve the physiological Reactive Oxygen Species (ROS) scavenging system, to counteract the oxidative stress induced by COVID-19, as well as the favorable rheological and tissue perfusion properties to limit the ischemic damages to the lung.

We believe the therapeutic effect of ozone is maximized in the early development of the disease when blood oxygenation is hampered by interstitial edema and exudation of fluid into the alveoli, but only with a limited extension of lung tissue consolidation. In this evolving phase the respiratory function can be supported without invasive mechanical ventilation. It is this the clinical evolution described by CT feature as ground glass opacities image and crazy paving appearance. Ozone treatment in this phase can prevent further evolution of lung damage. On the opposite, when major pulmonary damage has occurred and extended lung consolidation has arisen, a marked structural and histological

Carlo Tascini

c.tascini@gmail.com

1 SOC Anestesia e Rianimazione Uno, Università di Udine e Azienda Sanitaria Universitaria Integrata Di Udine, Udine, Italia

2 U.O. Malattie Infettive, Dipartimento di Medicina dell'Università di Udine, Università di Udine e Azienda Sanitaria Universitaria Integrata Di Udine, Udine, Italia

3 U.O. Lipoapheresis and Center for Inherited Dyslipidemias, Fondazione Toscana Gabriele Monasterio, Pisa, Italy subversion of the lung takes places and the CT images depicts a diffuse infiltration of the lung with extensive consolidation and atelectasis; in such situation ozone benefit are very poor and difficult to be detected.

The low number of $\mathrm{O}_{3}$-autohemotherapy $\left(\mathrm{O}_{3}\right.$-AHT $)$ sessions we performed in our experience, was accordingly with the satisfactory clinical results and the enormous number of admitted patients to take care.

We agree with Chirumbolo et al. [1] that the use of an instrumentation equipped with a high sensitivity spectrophotometer for a reliable gaseous mixture generation is mandatory. Accordingly, in our clinical activity we used the OZO2FUTURA (ALNITEC) which is fully furnished for an accurate and controlled ozone generation. Blood sample were collected in dedicated bags (TEC876-35 TECNO3; TECNOLINE) containing $35 \mathrm{ml}$ of anticoagulant citrate dextrose solution (ACD-A) and designed to be operated as a complete closed circuit. The reinfusion of $200 \mathrm{ml}$ of ozonized blood was started after $10 \mathrm{~min}$ of gently mixing with $200 \mathrm{ml}$ of $\mathrm{O}_{2} / \mathrm{O}_{3}$ containing $40 \mathrm{mcg} / \mathrm{ml}$ of ozone. This was the standard daily application to all treated patients, on the basis of previous experience in vascular patients [3] in whom the redox imbalance was certainly less important than in COVID subjects, with the aim to avoid excess anti-oxidant system stimulation.

Regarding the monitoring of $\mathrm{SPaO}_{2}$ during ozonized blood reinfusion, we did not perform it because in previous sessions we tested the efficacy of the method of blood mixing performing a gas analysis of the collected blood before and after ozonation, the $\mathrm{O}_{2}$ partial pressure increased of a factor of 7-10, with values higher than $500 \mathrm{mmHg}$.

Furthermore, Hernández A et al., in a prospective case-control study, confirm that ozonated autohemotherapy was associated with a significantly shorter time to clinical improvement [4]. In this study the total dose of gas mixture oxygen-ozone administered was similar to the one used in own study [2] even if spread over five consecutive days [4]. 
To confirm our preliminary data a multicenter prospective randomized study of adjuvant $\mathrm{O}_{3}$ - AHT is currently ongoing [ClinicalTrials.gov ID: Z7C2CA5837]. In this study, other than clinical aspects, were also evaluate inflammatory biomarkers, as interleukins, which we hope will confirm recent preliminary evidence [5].

\section{Acknowledgements None.}

Author contributions ADM, GS, ES, FS, CT: manuscript preparation. All authors gave final approval to the manuscript.

Funding No financial support was received.

\section{Compliance with ethical standards}

Conflict of interest CT has received funds for speaking at symposia organized on behalf of Pfizer, Novartis, Merck, Angelini, Zambon, Thermofischer, Biotest, Gilead, Hikma, Biomerieux and Astellas. All other authors declare that they have no conflict of interest.

Human and animal rights This article does not contain any studies with human participants or animals.

Informed consent For this type of study, formal consent is not required.
COVID-19 pneumonia: a single centre experience. Comment Intern Emerg Med. https://doi.org/10.1007/s11739-020-02542-6

2. Tascini C, Sermann G, Pagotto A, Sozio E, De Carlo C, Giacinta A, Sbrana F, Ripoli A, Castaldo N, Merelli M, Cadeo B, Macor C, De Monte A (2020) Blood ozonization in patients with mild to moderate COVID-19 pneumonia: a single centre experience. Intern Emerg Med. https://doi.org/10.1007/s11739-020-02542-6

3. de Monte A, van der Zee H, Bocci V (2005) Major ozonated autohemotherapy in chronic limb ischemia with ulcerations. J Altern Complement Med 11:363-367

4. Hernández A, Viñals M, Pablos A, Vilás F, Papadakos PJ, Wijeysundera D, Bergese SD, Vives M (2020) Ozone therapy for patients with COVID-19 pneumonia: a preliminary report of a prospective case-control study. Int Immunopharmacol. https://doi. org/10.1016/j.intimp.2020.107261

5. Franzini M, Valdenassi L, Ricevuti G, Chirumbolo S, Depfenhart M, Bertossi D, Tirelli U (2020) Oxygen-ozone (O2-O3) immunoceutical therapy for patients with COVID-19. Preliminary evidence reported. Int Immunopharmacol 88:106879. https://doi. org/10.1016/j.intimp.2020.106879

Publisher's Note Springer Nature remains neutral with regard to jurisdictional claims in published maps and institutional affiliations.

\section{References}

1. Chirumbolo S, Pandolfi S, Valdenassi L, Bertossi D, Franzini M (2020) Blood ozonization in patients with mild to moderate 